\title{
Deseo, revuelta y soberanía en Bataille, Blanchot y Didi-Huberman
}

\author{
Desire, revolt and sovereignty in Bataille, Blanchot and Didi-Huberman
}

\author{
SOL MARÍA JAIT SOLA'
}

\begin{abstract}
Resumen: Este trabajo es un ejercicio dialógico entre Georges Bataille, Maurice Blanchot y Didi-Huberman. Se postularán como ejes centrales de dicho diálogo la noción de revuelta y el movimiento surrealista. La hipótesis que guía este texto es el posible vínculo entre lo irresoluble y la soberanía a partir del deseo. Se reconocerá al surrealismo como marco teórico-estético desde el cual se nutren y posicionan dichos pensadores, ya sea como referentes o lectores. Se analizarán las redes que se tejen entre los siguientes conceptos: soberanía, revuelta y sumisión. Y, finalmente, se pensará la esfera del deseo (en vínculo con el juego y lo irresoluble) como aquel sustrato ontológico que permite que la soberanía humana sobreviva.
\end{abstract}

Palabras claves: surrealismo; revuelta; deseo; soberanía; juego; Georges Bataille; Maurice Blanchot; Georges Didi-Huberman.

Abstract: This work is a dialogical exercise between Georges Bataille, Maurice Blanchot and Didi-Huberman. The notion of revolt and the surrealist movement will be postulated as central axes of this dialogue. The hypothesis that guides this text is the possible relation between the unsolvable and sovereignty through desire. The surrealism will be recognized as a theoretical-aesthetic background from which these philosophers are nourished and positioned, either as referents or readers. We will analyze the networks woven between the following concepts: sovereignty, revolt and submission. And, finally, we will think of the sphere of desire (in connection with the game and the unsolvable) as that ontological substratum that allows human sovereignty to survive.

Keywords: surrealism; revolt; desire; sovereignty; game; Georges Bataille; Maurice Blanchot; Georges DidiHuberman

Cómo citar: Jait, S. (2020). Deseo, revuelta y soberanía en Bataille, Blanchot y Didi-Huberman. Cuadernos Filosóficos, I7. DOI: https://doi.org/10.35305/cf2.vi17.98

Publicado bajo licencia Creative Commons Atribución-SinDerivadas 4.0 Internacional [CC BY-ND 4.0] 


\section{Introducción}

En el siguiente artículo me propongo realizar un ejercicio dialógico entre Georges Bataille, Maurice Blanchot y Didi-Huberman, teniendo como ejes centrales de dicho diálogo la noción de revuelta y el movimiento surrealista. Tomaré como referencia la sugerente cita de Bataille: “...un mundo cuyas contradicciones estuvieran resueltas ya no tendría un fin soberano" (2008, p. 242), para pensar como hipótesis problemática -de este breve recorrido por estos autoresla relación que existe entre lo irresoluble y la soberanía y el particular acercamiento que se da entre ambas esferas a partir del deseo.

En primer lugar, reconoceremos al surrealismo como marco teórico-estético desde el cual se nutren y posicionan nuestros pensadores, ya sea como referentes o lectores. Esbozaremos una definición del surrealismo a partir de lo expresado por Bataille en "La religión surrealista" (2009) y por Blanchot en "El mañana jugador" (2008).

Luego, visualizaremos las redes que se tejen entre los siguientes conceptos: soberanía, revuelta y sumisión, tal como son abordados por Bataille en "El soberano" (2008a) y en “Estamos aquí para jugar o para ser serios?” (2008b) y por Didi-Huberman en "Por los deseos (Fragmentos sobre lo que nos subleva)" (2017), específicamente en los apartados: "Desde las profundidades" y "Potencia contra poder, o el acto del deseo".

Finalmente, pensaremos la esfera del deseo (en vínculo con el juego y lo irresoluble) como aquel sustrato ontológico que permitiría que la soberanía humana sobreviva.

\section{Bataille y Blanchot frente al surrealismo}

En "La religión surrealista", Georges Bataille caracteriza al surrealismo como una actitud, una efervescencia, incluso como una voluntad. Creo que la clave de la consideración batailleana es que piensa al surrealismo en lo filosófico como una exploración hacia una vida más soberana y una realidad más profunda; exploración sin teleología que busca "ese elemento irreductible por el cual el hombre sólo puede asemejarse perfectamente a una estrella" (Bataille, 2009, p. 47). Bataille encuentra, en este sentido, que el surrealismo comparte con la religión una insistencia por lo sagrado, y, en conexión con ello, un avocamiento hacia los ritos del hombre primitivo, puesto que en los ritos se buscan "las formas más agudas y más tangibles de la vida poética” (2009, p. 47). 
Maurice Blanchot, a su vez, afirma que el surrealismo no es ni una empresa de renovación literaria, ni un movimiento de arte, ni tampoco un discurso filosófico $\circ$ un tipo de acción política; el surrealismo, por el contrario, es práctica de existencia, "práctica de conjunto que lleva su propio saber, una teoría práctica” (Blanchot, 2008, p. 523).

Ya a partir de estas primeras caracterizaciones podemos notar, en ambos autores, que el surrealismo se piensa no como un simple ismo o como una teoría particular, sino como una forma consciente -pero no por ello personal- de habitar el mundo y de relacionarse con el universo. El surrealismo ha sido y es -dirá Blanchot- experiencia colectiva.

Tanto Bataille como Blanchot advierten que el surrealismo es víctima de una opresión en la que se encuentra sumergida la humanidad de su tiempo. La naturaleza humana, según Bataille, está sometida por la necesidad del trabajo técnico, en tanto dicho trabajo subordina todas las acciones y los juicios de los hombres a un resultado ulterior: un logro material. En este sentido, la lógica productivista y consumista del capitalismo altera la relación del hombre con el universo, separando a uno del otro y dejando al hombre en cierto modo huérfano y desprovisto de soberanía. Por su parte, Blanchot postula que nos encontramos sometidos a la ideología de lo continuo; esta ideología identifica la realidad con un modelo -lo continuo/la plenitud del ser- que se presenta como lo único realmente real, pero que el hombre -por su condición imperfecta- sólo puede conocer de forma discontinua y limitada.

Esta situación de subordinación e incluso de humillación de la naturaleza humana provoca la sublevación del surrealismo como respuesta vital antes que obra o teorización. Podemos pensar, entonces, al surrealismo como revuelta, y, en primer lugar, como revuelta desde y contra el lenguaje. Bataille se pregunta: “¿Cómo podría tener lugar [lo que podríamos llamar: el advenimiento de la posibilidad] mientras dos seres están profundamente separados por el interés personal que existe en cada uno de ellos?" (2009, p. 5I). Es por ello que, según el escritor francés, en la actitud surrealista el cuidado del interés personal y el afán de durar y asegurar los intereses materiales de uno mismo -que pregona el capitalismo- deben desaparecer bajo la forma del escándalo. Ahora bien, Bataille encuentra en lo antedicho un límite para el surrealismo (límite que comparte así mismo con el comunismo): es imposible escapar del mundo capitalista y "no podemos conocer directamente una vida en la que el interés personal se hubiera suprimido" (2009, p. 50). Pero este límite se muestra -como 
explica Silvia Schwarzböck ${ }^{2}$ - también como su posibilidad: el surrealismo es voluntad de lo imposible ${ }^{3}$. Solo hundiéndonos en la conciencia podemos intentar transgredir las dificultades del mundo actual; de lo que se trata, para Bataille, es de unir la conciencia con la despersonalización. El surrealismo "se adentró profundamente en esta vía" pero, para el autor, “esta vía permanece abierta y [...] es necesario adentrarnos aún más” (Bataille, 2009, p. 5I).

Según Blanchot el surrealismo es una pluralidad extraña. Lo surreal -etimológicamente el prefijo 'sur' en francés significa 'sobre', es decir, lo que amplía o abunda 'por encima' de lo real- abre un espacio múltiple en el cual lo desconocido entra y no sólo no se deja unificar, sino que tampoco "coincide nunca con el acuerdo que unos individuos, agrupados alrededor de una fe, un ideal, un trabajo, pueden sostener en común" (Blanchot, 2008, p. 526). No se trata, entonces, del pensamiento personal de un sujeto o de un conjunto de sujetos, sino del funcionamiento real del pensamiento -dirá Blanchot- que se encuentra emancipado, es decir, sin referencia a un único poder de decir. Lo que adviene, en el surrealismo, es el encuentro, encuentro que traspasa el mundo y que traspasa el yo: "Siempre, aunque fuere en el corazón más íntimo de la interioridad, se trata de la irrupción del afuera, la exterioridad que lo sacude todo" (Blanchot, 2008, p. 533)

El lugar por excelencia donde el surrealismo encuentra su plenificación y exaltación -y por cuyo encuentro se define- es la escritura. Pero escritura de otra clase -afirma Blanchot"escritura sin nadie que escriba, pasiva, es decir, pura pasión, indiferente, porque lleva consigo toda diferencia; escritura de pensamiento (y no pensamiento escrito)" (2008, p. 530). Es escritura automática liberada de la lógica del lógos, que llega en la incertidumbre y en el tiempo de la sorpresa; escritura que rechaza todo lo que la hace obrar, es decir, que reniega de la ideología que reduce el lenguaje a una simple mercancía, a un valor de usufructo e intercambio. También para Bataille lo que caracteriza esencialmente a la escritura automática es un acto de ruptura, acto de sublevamiento contra un encadenamiento que se da en las palabras mismas. La fuerza del lenguaje -en el mundo de la actividad técnica- ha sido cooptada

2 En sus lecciones teóricas de Problemas Especiales de Estética, materia dictada en la carrera de Filosofía de la Universidad de Buenos Aires en el año 2020, Silvia Schwarzböck escribe: "Bataille presenta, de modo paradojal, los límites del surrealismo como si fueran sus posibilidades: "estamos, lo queramos o no, encerrados en el mundo capitalista; [...] no podemos conocer directamente una vida en la que el interés personal se hubiera suprimido".

3 "El surrealismo es voluntad de lo imposible" es una reformulación propia de la cita de Bataille: "No se trata de ninguna forma que pudiera conciliarse con la posibilidad, no hay nada de posible en el hecho de disparar contra la masa; disparar al azar en la masa significa exactamente la voluntad de lo imposible y nada más, en la medida en que después de todo nadie lo hace” (Bataille, 2009, p. 46). 
como simple materia de uso; pero "el lenguaje puede y debe ser arrancado de su servidumbre" (Blanchot, 2008, p. 527). El surrealismo es quien lleva a cabo este mandato. Sin embargo, es importante destacar que se trata de un mandato sin meta y sin programa. Blanchot dice que el surrealismo se afirma siempre por venir, esto significa que no hay un proyecto a cumplir o un fin determinado; el surrealismo se caracteriza, más bien, por la espera de lo inesperado.

La escritura automática, entonces, es gesto de insubordinación; quien escribe olvidándose de quién es, desafiando lo instituido como real y atreviéndose a jugar en el campo de lo incierto realiza un acto soberano y experimenta -afirma Bataille- una destrucción de la personalidad. Experimentación surrealista, pensamos, que está por fuera de la lógica del éxito y del fracaso. Blanchot explica que es experiencia -que no obedece al orden reinante de la experiencia- que se da en un espacio de diferencia en el cual "lo desconocido se anuncia y entra, fuera de juego, en el juego" (2008, p. 542). Blanchot designa con las palabras juego/albur/azar este lugar de tensión en el cual irrumpe y se despliega lo indeterminado/lo neutro.

\section{Sumisión, revuelta y soberanía}

Retomemos los conceptos de sumisión, revuelta y soberanía en relación con lo expuesto por Didi-Huberman. Comencemos por la noción de sumisión. ¿A qué estamos sometidos? Bataille responde: "la humanidad se sometió por sí sola en su conjunto [...] a la ley del trabajo y a las grandes prohibiciones. Se sometió, renunció a la soberanía natural del animal” (2008, p. 233). La humanidad, para humanizarse a sí misma -y distinguirse del animal-, se sometió a una servidumbre voluntaria: al mundo del trabajo y la seriedad; mundo que podemos caracterizar por el saber, el cálculo, la previsión y la utilidad.

Sin embargo, en este mundo de quietud y conservación hay algo que se sustrae: un trasfondo insensato "que configura ya la imaginación, ya el desorden, y a veces la tensión extrema de la vida, [que] se sustrae sin duda alguna a toda racionalización concebible" (Bataille, 2008 , p. 242). Frente a una lógica de sumisión -de previsión y racionalidad al servicio del futuro- hay algo en el tiempo presente que se subleva, hay algo que es indestructible dirá DidiHuberman -retomando a Freud-: "la potencia psíquica como tal, es decir, el deseo" (2017, p. 103).

El deseo parece ser indestructible, o de serlo arrasaría consigo el alma humana de la niña que comete atentados, del niño insumiso, del rebelde. Todos ellos, y cada uno a su manera 
-“no somos todos ni somos igualmente rebeldes en idéntica forma” (Bataille, 2008, p. 229)desean y desean porque no están satisfechos. El deseo entonces es fuerza de sublevación, de revuelta. Didi-Huberman afirma: "Nadie ha expresado mejor que Bataille el valor transgresor del deseo como potencia de sublevación" (2017, p. 109).

La revuelta parte de un movimiento negativo: el rechazo, movimiento que acontece en el instante, justamente porque no está subordinado a un futuro, porque se escapa y reniega de las consecuencias; rechazar es una fuerza fundamental, es "la insumisión de un niño deseoso de escapar del marco paterno y ansioso de sus propios movimientos libres" (Didi-Huberman, 2017, p. 92).

El rechazo, cabe precisar, no es solo el movimiento de rechazar cierto estado injusto e intolerable de lo que nos rodea, sino que y sobre todo -explica Didi-Huberman-es el hacer otra cosa. En el sobresalto del rechazo (en palabras batailleanas) se abre otro mundo. Cuando se desplaza el rebelde, podemos pensar que desplaza consigo el sentido. Ese desplazamiento o apertura es fundamentalmente potencia -la potencia de hacer de otro modo- que nos abrirá, según Bataille, a una experiencia más ardiente.

Pero, ipor qué potencia más bien que poder? Ante la dialéctica hegeliana del Amo y el Esclavo, Bataille se figura la siguiente situación: en la lucha a muerte el Amo prefiere arriesgar su vida a ser sometido -su actitud implica soberanía-; el Esclavo, en cambio, cede su vida porque prefiere no morir. Ahora bien, la soberanía humana necesita ser reconocida -sino, afirma Bataille, sería "la soberanía de un zorro o un mirlo" (2002, p. 312)- y por eso el Amo no puede matar a su adversario, sino que tiene que reducirlo a la esclavitud. En el momento en que el Amo se convierte en Amo de esclavos pierde su belleza impotente, porque transforma su potencia en poder. El poder se subordina a la lógica de la sumisión en cuanto su fin es someter a otros y convertirlos en útiles. La potencia, en cambio, es soberana porque está caracterizada -dirá Didi-Huberman- por un no poder persistente. La sublevación es potencia no instituyente, no busca el poder, y por tanto, no se agota jamás; la potencia es "la energía misma -energía indestructible- de nuestros deseos” (Didi-Huberman, 2017, p. 105).

Ahora bien, nos preguntamos ¿qué mueve al movimiento de la revuelta? $\mathrm{O}$, en palabras de Didi-Huberman: “QQué nos subleva? Son fuerzas, evidentemente” (2017, p. 83), responde el autor, y luego añade: “Uno se rebela para manifestar su deseo de emancipación” (2017, p. 92). Es el deseo de ser libres lo que nos subleva. 
La revuelta aparece así entretejida con el deseo de soberanía. Pienso, incluso, que la revuelta es ella misma gesto inocente de soberanía. Didi-Huberman expresa: "Incluso antes de afirmarse como actos o como acciones, las sublevaciones surgen del psiquismo humano como gestos: formas corporales" (2017, p. 93). Los gestos revoltosos en sí mismos son atentados contra la quietud, por ejemplo: las sábanas levantadas por el aire, agitadas vertiginosamente 0 "la niña [que] ataca la colocación ordenada del mobiliario, la aparente ley de las cosas en el interior de una casa" (Didi-Huberman, 2017, p. 92).

Ser soberano implica, entonces, salir -o escapar- del espacio de la sumisión, en cierta manera destruir las respuestas históricas que el ser humano se ha dado a sí mismo -tirar el dolor por la borda-, y permitirse jugar por fuera del paradigma de lo útil y lo necesario.

Didi-Huberman afirma: "En las sublevaciones la memoria arde: consume el presente y, con este, cierto pasado, pero descubre también la llama oculta bajo las cenizas de una memoria más profunda" (2017, p. 100). Podemos pensar esta memoria más profunda en analogía con el cante jondo, o 'cante profundo', y la figura -retomada por Didi-Huberman- del duende de García Lorca: "si el ángel nos eleva y la musa nos cautiva, el duende nos subleva desde sus profundidades ignoradas, que son nuestras mociones interiores, nuestros deseos más extremos" (Didi-Huberman, 2017, p. 93).

El impulso fundamental de la sublevación no proviene de alguna trascendencia religiosa, ni tampoco de algún ideal artístico, sino de la fuerza profunda de la rebelión; de "las cóleras y la energía de insubordinación de los pueblos que sufren” (Didi-Huberman, 2017, p. 93); el cante jondo debe su fuerza al deseo de emancipación.

Este duende que 'sube por dentro' y nos subleva, se manifiesta no en las ideas sino particularmente en el gesto. Es el gesto el que sobrevive -en la memoria más profunda- y el que se transmite "pese a nosotros mismos y pese a todo" (Didi-Huberman, 2017, p. 94). Para Didi-Huberman, es en la historia gestual de los pueblos -en lo sensible de los gestos- donde podemos reconocer el movimiento mismo de las sublevaciones.

También la pérdida -la falta- es fuerza de sublevación, afirma Didi-Huberman. El deseo humano, pienso, está ligado a una pérdida cuyo duelo nos es imposible. Bataille nos advierte: "No queda en verdad nada y no se muestra nada en el universo que pueda confirmar o guiar la existencia incierta del hombre" (2008, p. 243). 
Es aquí donde encuentro esta particular relación que se genera entre el deseo y lo irresoluble. Deseamos porque nos falta infinitamente, deseamos porque el mundo -en sus contradicciones- no puede ser resuelto.

\section{El juego: lo incognoscible, la muerte y el peligro}

Sin embargo, hay un dilema, explica Bataille: incesantemente se le impone al humano la necesidad de elegir entre jugar con el mundo y la vida y desafiar a la muerte, o bien someterse al mundo del trabajo, y considerar a éste y a la muerte como serios. Es decir, el humano puede refugiarse por miedo en la sumisión, o puede jugar y sublevarse.

Pero además de advertirnos sobre nuestra existencia incierta, Bataille también nos anuncia algo: "El pensamiento que fundaron el trabajo y la coacción ha fracasado; es tiempo de que habiéndole cedido al trabajo, a lo útil, el lugar monstruoso que conocemos demasiado bien, el pensamiento libre recuerde finalmente que, en el fondo, es un juego (un juego trágico), y que la humanidad entera, también [es] un juego" (2008, p. 219).

El juego, según Bataille, es lo que no tiene finalidad ni tampoco razón; es lo que escapa de los límites de la producción y de la utilidad. La categoría del juego hace perceptible "la caprichosa libertad y el encanto que anima los movimientos de un pensamiento soberano, no sometido a la necesidad" (Bataille, 2008, p. 192). Bataille distingue entre un juego menor aquél que es asimilado y tolerado por el mundo del trabajo y lo útil- y un juego mayor, que define como revuelta plena, como don soberano que no se subordina a un fin.

Lo incognoscible y la muerte signan el movimiento del juego, así como también -expresa Bataille- el nacimiento de la filosofía; sin embargo -añade el autor- parece que, a lo largo de la historia, la filosofía "se remitió al trabajo y, en el plano del enigma insoluble, se confió a los métodos que habían sobresalido en el plano del conocimiento" (2008, p. 218).

De este modo Bataille critica el devenir de la filosofía -que renegó del juego y de lo incognoscible- y la responsabiliza por el estado actual de la humanidad, pero también, al finalizar su ensayo, pronuncia: "La revuelta es el placer mismo y es también lo que se juega con todo pensamiento” (Bataille, 2008, p. 244).

Retomando a Maurice Blanchot, el autor caracteriza al espacio del juego como un espacio peligroso. Hay un riesgo en este campo "no unificado, no legalizado y sin senda donde la vida ya no se da más en el ámbito de lo real" (Blanchot, 2008, p. 536). Es el peligro, -por donde 
según Blanchot- se introduce, en vez de la obra, la desobra o el juego de la ausencia de obra. La ausencia es tematizada también por Bataille, para quien, el fundamento de toda comunidad posible es la ausencia de comunidad, así como, toda comunicación poética es posible sólo en la medida en que la poesía es llevada hasta la ausencia de poesía. El encuentro de la experiencia surrealista, dirá Blanchot, sale a escena necesariamente en esa continuidad del mundo para romperla -descomposición del mundo- y para afirmarse como "interrupción, intervalo, detención o abertura" (2008, p. 532). Es una salida a escena que pone todo en tela de juicio -la vida, el pensamiento, el amor, el habla, el tiempo, etc.- $y$, rechazando el orden del todo -el mundo para Blanchot es ontológicamente discontinuo-, provoca que la condición de la realidad presente se vea definitiva o momentáneamente cambiada a partir del advenimiento de lo indeterminado.

La efervescencia surrealista, en palabras batailleanas, es un estado de lucidez y presencia; un estado de vigilia que permite que se restablezca necesariamente la imposibilidad de un límite entre los hombres en la conciencia y entre la humanidad y el resto del universo. El surrealismo, de esta manera, encuentra lo sagrado en la inmanencia o, como dirá Blanchot, dichas categorías dejan ya de tener sentido: "Llámese lo maravilloso, lo superreal o de otro modo (en cualquier caso, aquello que desacredita tanto la trascendencia como la inmanencia)" (2008, p. 526). El surrealista encuentra la soberanía de ese elemento irreductible que se encuentra en el hombre: la simpleza de la pasión; elemento mediante el cual retorna a una vida mucho más libre, noble y salvaje y por la cual -ahora entendemos- puede asemejarse perfectamente a una estrella.

Podemos sospechar, entonces, que hay un residuo enigmático que no es ajeno al pensamiento; esta esfera enigmática, que pienso que es posible nombrar como lo irresoluble, permite que el deseo sobreviva y que se exprese soberanamente en el juego, en el gesto, en la sublevación y también en el pensamiento. La revuelta, a su vez, también es placer porque hay algo grato en el jugar; "todo se juega como una fiesta" (Bataille, 2008, p. 191), y en francés jouer también tiene el sentido de interpretar o efectuar. De la misma manera, para DidiHuberman, el acto de sublevación es fundamentalmente alegría, y la alegría -explica- es expansiva: "ensancha, dilata el mundo a nuestro alrededor y nos pone a su ritmo" (DidiHuberman, 2017, p. 90).

Me atrevo a decir, finalmente, que El soberano de Georges Bataille es quien aprecia la oscuridad del universo -lo irresoluble- $y$ desea jugando, sin esperar una respuesta. 


\section{Referencias}

Bataille, G. (2002). Hegel, el hombre y la historia. En La felicidad, el erotismo y la literatura, Ensayos 1944-196I. Adriana Hidalgo.

Bataille, G. (2008a). El soberano. En La felicidad, el erotismo y la literatura. Ensayos 1944-196I (pp. 227-244). Adriana Hidalgo.

Bataille, G. (2008b). ¿Estamos aquí para jugar o para ser serios?. En La felicidad, el erotismo y la literatura. Ensayos 1944-196I (pp. 186-219). Adriana Hidalgo.

Bataille, G. (2009). La religión surrealista. Ramona. Revista de Artes Visuales, 96, 46-53.

Blanchot, M. (2008). El mañana jugador. En La conversación Infinita. Arena Libros.

Debord, G. (2008). La Sociedad del Espectáculo. La Marca.

Didi-Huberman, G. (20I7). Por los deseos (Fragmentos sobre lo que nos subleva). En S. Wechsler (ed.), Sublevaciones. MUNTREF.

Jay, M. (2007). Ojos abatidos. La denigración de la visión en el pensamiento francés del siglo $X X$. Akal.

Schwarzböck, S. (2017a). Los monstruos más fríos. Estética después del cine. Mardulce.

Schwarzböck, S. (20I7b). Las Medusas. Estética y Terror. Revista Instantes y Azares. Escrituras nietzscheanas, 19-20. 